\title{
Lean Inventory Management Systems and Performance of Supermarkets in Nairobi County, Kenya
}

\author{
Achuora John and Arasa Robert
}

\begin{abstract}
Lean inventory management systems (LIMS) is postulated to have the capability of enhancing performance of firms through minimization of overheads associated with inventory management in firms where inventory forms a significant portion of operational costs. Therefore in this study LIMS(s); just-in-time, cross-docking, drop shipping and backordering were theorized to have an impact on the performance of supermarkets in Nairobi County, Kenya. The study used of a descriptive research design and surveyed 113 supermarkets randomly sampled from 158 supermarkets in Nairobi City County. A structured questionnaire was used as the primary data collection intrument. The questionnaire was administered through drop and pick later mode to the respective supply chain managers of the supermarkets. The instrument was piloted for validity, reliability and to identify potential gaps. Multiple regression model was applied to test the study hypothesized model and the statistical package for social science (version 21.0) facilitated the tests. The tests established a positive significant link between lean inventory management systems and performance of supermarkets. This implies that an increase in use of lean inventory management systems in the operations of supermarkets, increases their performance positively. The study further established that just in time system had the highest influence on supermarkets performance followed by backordering, drop picking and cross-docking respectively. The study concludes that lean inventory management systems such as just-in-time, crossdocking, drop shipping and backordering improve supermarket performance. The study recommends that retail supermarket owners/managers should implement an inventory policy in support of lean inventory management practices, define stock keeping units to better understand and forecast demand. Secondly, supermarket owners should make profound cultural changes to re-enforce a lean transformation and develop a performance culture focusing continuous improvement where staff are always actively discussing and implementing improvements through either formal or informal. Finally supermarket owners/managers need to close the gap by hiring a few people with lean expertise and experience from outside the retail sector to seed the transformation and build new internal capabilities in lean inventory management practices in managing their inventory.
\end{abstract}

Index Terms - Backordering; Cross-Docking; Drop Shipping; Just-In-Time

\section{INTRODUCTION}

Owing to competitive nature of retail industry, firms are increasingly appreciating the value of efficient management of inventory as a differentiation strategy. Consequently, a number of firms are looking for modalities of making inventory management direct contributor to performance

Published on April 07, 2020

John Odoyo Achuora, Machakos University, Kenya.

(e-mail: kachuora78@gmail.com).
[2]; [8]. "Reference [8] reveals that the high cost of money involved, forced a re-evaluation of the benefits of holding inventory against not holding inventory". "Reference [17] explains that the volume of inventory determines the cost of managing it". Therefore, as explained by reference [17], inventory management is not only considered a cost-cutting method but according a competitive weapon which when strategically employed, would not only lower inventory carrying costs, but also improve market share and customer service levels, essentially improving performance for firms in the retail industry. [8], fronted lean inventory management as the dominant strategy in inventory management capable of significantly influencing performance hence the study.

Lean inventory management refers to a systematic approach to enhancing value in a company's inventory by identifying and eliminating waste of materials, effort and time through continuous improvement in pursuit of perfection and performance [20]. References [17], [8] and [20], identify practices such as just in time, backordering, crossdocking and drop shipping as some of the commonly used lean inventory management system (LIMS). According to reference [20], a firm can deploy more than one LIMS but cautions that, it is imperative that management installs optimal practices; the key to which is to identify the LIMS that best suit the business' needs and having the tools to put them into effect efficaciously and efficiently [20].

\section{Supermarkets in Kenya}

Kenyan retail stores encompasses a mixture of big supermarkets which provide fast moving consumer goods, home appliances, electrical and hardware items, textiles and many other items. The industry composed of both multinationals firms and local firms large [3]. The major players has been; Nakumatt with 57 branches, Tuskys 45 branches, Naivas 36 branches and Uchumi 27 branches [11]. However, the dominance structure has since change in the past three years which have seen Nakumatt, Ukwala and jack and Jill closed shops, Uchumi became a shell of its past and a number current dominants such as Tuskys and Naivas are struggling to remain a float majorly due to overbearing overheads [11]; [18].

This is despite high expectation from the industry to be one of the key drivers of socio-economic growth towards the realization of the Vision 2030 and the Big 4 agenda by the government [18]. At minimum, the industry is expected to contribute 10 percent of the GDP and 10 percent of the total formal employment for it to significantly contribute to the attainment of Vision 2030 and the government Big 4 agenda. This notwithstanding, the current trend in the retail industry has seen owners, managers and policy makers doubt the capacity of the industry to effectively play its role in the realization of the country's development road maps 
[11]. This has seen managers and owners of various retail ventures trying new strategies aimed at changing performance level through reduction of operations cost and increased efficiency in the activity chain of retailing. Within the emerging strategies, lean inventory management system has stood out however, there is no empirical quantum befits to support its use as a strategy with the potential to turn around the fortune of retail industry in Kenya.

\section{STATEMENT OF THE PROBLEM}

In the last three years, retail industry in Kenya has seen significant changes within its dominance structure which has seen the lesser firms of yester years becoming the major players and the yester years' major players becoming extinct or struggling to remain a float [11]. For example; Nakumatt, Ukwala and jack and Jill closed shops, Uchumi became a shell of its past and a number current dominants such as Tuskys and Naivas are struggling to remain a float majorly due to overbearing overheads [11] ; [18]. This has seen the contribution of the retail sector to the GDP progressively decline; standing at 8.0 percent in 2014 and further declining to 7.5 percent as at 2015 [9]. This is despite high expectation of the industry to be one of the key drivers of socio-economic growth towards the realization of the Vision 2030 and the Big 4 agenda by the government [18]. At minimum, the industry is expected to contribute 10 percent of the GDP and 10 percent of the total formal employment for it to significantly contribute to the attainment of Vision 2030 and the government Big 4 agenda [9].

Based on the performance trend as per the [9] report, the contribution of the sector towards realization of the Vision 2030 and the government Big 4 agenda is in doubt [9] hence an attempt by retail owners and managers of a number of new operation strategies focusing on performance improvement [11]; [2]. Within these strategies, lean inventory management system has stood out [20], however, there is no empirical quantum befits to support its use as an operation strategy with the potential to turn around the fortune of retail industry in Kenya through increased performance [20]. Thus, this study sought to establish the influence LIMSs on the performance of supermarkets taking Nairobi City County as a representative sample.

\section{RESEARCH OBJECTIVES AND HyPOTHESISES}

The study aimed at establishing the influence of lean inventory management systems on the performance of supermarkets in Nairobi City County, Kenya. Anchored on the objective, the study was guided by the subsequent precise objectives: to ascertain the influence of just-in-time, cross-docking, drop shipping and backordering systems on the performance of supermarkets in Nairobi City County. The study tested the ensuing null hypothesises in an attempt to address the study objectives; there is no relationships between just-in-time system, cross-docking systems, drop shipping system and backordering system and the performance of supermarkets in Nairobi City County, Kenya?

\section{RATIONALE AND SCOPE OF THE STUDY}

The performance issues of supermarket required urgent attention in order to find sustainable strategies which could guarantee expected results. Therefore, this study was informed by the urge to craft a strategy which could change the dwindling performance of the supermarkets and offer a sustainable solution to the inventory operational challenges of the supermarkets, taking Nairobi City County as a sample. The City County is home to the largest number of supermarkets in the country and hosts all kind of supermarkets. The study therefore, advanced lean inventory management systems namely: just-in-time, cross-docking, drop shipping and backordering systems as solutions to the declining performance of supermarkets in Kenya. Profitability was used as a measure of firm performance [11] - [13]. Heads of supply chain management were preferred as the respondents and the data was collected between January, 2019 and March, 2019.

\section{THEORETICAL AND CONCEPTUAL FramewOrK}

This section provides theatrical foundation of the study as discussed in the section to follow. A conceptual framework (Fig. 2.1) was formulated based of the theoretical for testing.

\section{A. Theoretical Framework}

This study was grounded on the Resource Based View Theory (RBVT) which was advanced by [7]. The resource based view theory states that the resources and capabilities of a firm are fundamental for the formulation of an effective strategy for a firm. [7] reveals that firms have within their possession resources which are unique and rare that can be deployed effectively to differentiate them from their competition. Reference [4] advanced LIMs as one of such resources with the potential to offer cost leadership and exemplary customer service to firms. According to [18], unique and rare practices such as just in time, cross docking, drop picking and backordering have been conceptualized and deployed with significant and positive results by a number of firms in Europe and America. [18] content that LIMs are priced and uncommon management processes whose benefits can be utilized by the firms to afford momentary competitive advantage as well as sustainable competitive advantage depending on the extent to which the firm is able to protect against resource imitation, transfer, or substitution [4]-[9].

Therefore, RBVT expects firms to consider their own internal processes and systems to try and assess the possible strategies which can be grounded on them to achieve performance road map [7]. Anchored on [18] postulation that LIMs are key internal systems which are valuable, rare and convertible to strategies capable of affording cost, quality and customer service differentiation, the study used RBVT to conceptualize the relationship between LIMSs (just in time system, backordering, cross-docking and drop shipping) and performance of supermarkets in Nairobi City County, Kenya. 


\section{B. Conceptual Framework}

Based on the theoretical review, the study hypothesized a relationship between lean inventory management systems and performance of supermarkets in a model format (Fig. 2.1) for testing. The model presents just in time system, backordering, cross-docking and drop shipping as independent constructs and performance as the dependent construct:

\section{Independent Variables}

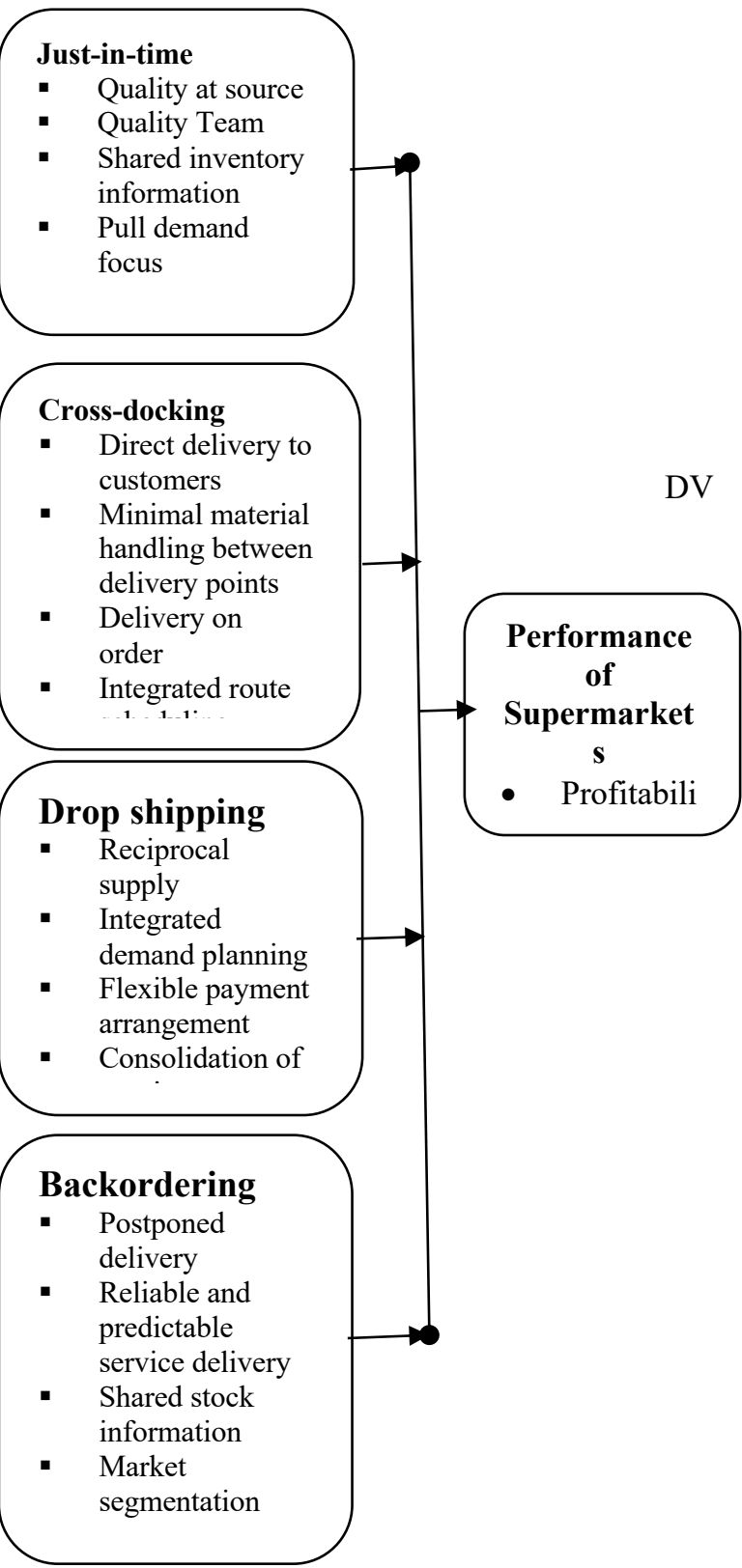

Figure V.1: Conceptual Framework

\section{C. $\quad$ Lean Inventory Management Systems and Firm} Performance

Womack et al in 1990s, pioneered lean thinking in the management science to identifying and minimizing wastages and smoothen organizations' operations [13]. This was later propagated extensively within management cycle [12]. Consequently, a number of studies have attempted to relate lean practices with performance of firms. For example, [12] study which applied descriptive research design to survey 125 retail firms in Frankfurt established a positive and significant results between lean inventory management systems and performance. The study used just in time, vendor managed inventory, cross docking and drop picking as lean inventory management practices, the independent factors, and profitability as performance indicator, the dependent factor. "Reference [8] concluded that lean retailing reduces inventory levels and stock outs".

Further, [8] used cross-sectional survey research design on 246 manufacturing firms and established a positive relationship between lean inventory management systems and firm performance. The study used multiple regression model to regress cross-docking, backordering, drop picking, and just in time against profitability of the firms. Reference [13] surveyed logistics firms and established that drop picking influences performance of firms through reduction of transportation, wear and tear of vehicles and logistics efficiency. In their support, reference [19] established that drop-shipping pools risks within multiple retailers hence increase in product availability which augments customer satisfaction and improves profitably. Additionally, [18] concluded that backordering, cross -docking, drop picking and just in time cut operation since what is coming in has already been scheduled, therefore no holding costs.

\section{RESEARCH METHODOLOGY}

This section presents the study framework which outlines the methods used to collect, collate, analyse and present the study findings. Further, it specify the unit of analysis and the unit of observation applied in the study. Finally, it presents the method used to test both validity and reliability of the data collection instrument.

\section{A. Research Design and Target Population}

The study used descriptive cross sectional survey research design to establish the influence of strategic inventory management practices on the performance of supermarkets in Nairobi County. Descriptive cross sectional survey research design was preferred because of its ability to provide a good picture of exposure and outcome, compare many variables at the same time and at minimum cost [15] at a given point in time. Further, the design is applicable when a large population is involved and in depth of information is required. Additionally, the design was preferred because it provides reports on things as they are [15].

The study used all the supermarkets in Nairobi City County as the target population. There were one hundred and fifty eight (158) supermarkets operating within the Nairobi City County, according to the Kenya bureau of statistics, 2017 records [23]. Nairobi City County was of interest because it hosts all kinds of supermarkets and about $50 \%$ of the total supermarket population in Kenya is based in Nairobi City County.

\section{B. Sampling Frame, Sample and Sampling Technique}

A list of 158 supermarkets from KNBS, (2017) was used as the study sampling frame. From the sample frame, 
the study used [22] model to compute a sample size of 113 supermarkets as follows:

$n=\frac{N}{1+N e^{2}}$ Where: $\mathrm{n}=$ Sample size, $\mathrm{N}=$ Population size, $\mathrm{e}=$ the error of Sampling $(0.05)$

Thus:-

$$
n=\frac{158}{1+158(0.05)^{2}}=113.261 \simeq 113
$$

From the computed sample size, the study used stratified random sampling procedure to select respondents. Stratified random sampling separate the population into mutually exclusive homogenous segments (strata), which in this study was the size of the supermarket (largescale/small-scale) [15]. With stratified sampling, the precision is higher compared to simple random sampling because the variability within the strata is lower compared to the variation when dealing with the entire population [15]. Further purposive sampling used to select the unit of observation based on their knowledge of the subject; inventory management.

\section{Data Collection Methods and Instrument administration}

Obtrusive data collection methods were used to collect primary data in the study. A questionnaire was used as the main primary data collection instrument. The questionnaire was preferred because it is easy to administer, analyse, provides a high degree of data standardization and adoption of generalized information amongst any populace [15]. Both closed and open questions were provided in the questionnaire and it had five sections in total. The first section focused on the general information about the respondents while sections two to five focused on information about LIMs and performance. The instrument applied Likert scales measurements ranging from one to five. The instrument was administered through drop and pick later technique where the respondents filled the questionnaire with the researcher picking them later. The technique was preferred due to its effectiveness on the response rate (Bowling, 2005).

\section{Pilot Test: reliability and validity tests}

The instrument was piloted on 10 respondents which was a $10 \%$ of the sample size [21] for reliability and validity. These group was not included on the main study. The study then used Cronbach alpha test to test for reliability of the instrument. A scale of 0.7 was applied and measures whose alpha scores were 0.7 and above were to considered reliable and below were to be rejected as not reliable measures [21]. All measures were however scored alpha above 0.7 and were therefore reliable. The used theoretical review to construct the study factors thereby ensuring logical validity.

\section{E. Data Analysis and Presentation}

The study used inferential statistics (multiple regression) to analyse quantitative data. Multiple regression model was preferred in this study due to its ability to model and analyse several. The model used was in the form of: $\mathrm{Y}=$ $\beta 0+\beta 1 \mathrm{X} 1+\beta 2 \mathrm{X} 2+\beta 3 \mathrm{X} 3+\beta 4 \mathrm{X} 4+\varepsilon$. Where:

$\mathrm{Y}=$ Dependent variable (profitability)

$\mathrm{X} 1=$ Vendor-managed inventory

$\mathrm{X} 2$ = Lean inventory systems

$\mathrm{X} 3$ = Information communication technology

$\mathrm{X} 4$ = Activity-based costing systems

$\varepsilon=$ Constant

The model measurement parameters were: the correlation co-efficient - ' $r$ ' which measured the strength and direction of the linear relationship between the variables, and Rsquared (R2) which showed what percentage of performance was impacted by the independent variables. A t-test was also done at a $p$-value of significance level $p \leq 0.05$. The study used SPSS version 23 to facilitate the analysis of the data. Tables and figures were used to present the study findings from various tests.

\section{FINDINGS AND DISCUSSIONS}

\section{A. Response Rate}

"Reference [24] establish that a response rate of $60 \%$ and above should be adequate in a social science research". For this study, a total of 120 respondents were issued with questionnaires, out of which, 114 questionnaires were filled and returned. This gave a response rate of $95 \%$. This was considered adequate in for this study according to [24] who assert that a response rate of $80 \%$ and above is excellent while that of between $60 \%$ and $80 \%$ is just sufficient for a study. Table 4.1 shows the response rate:

\begin{tabular}{llcc}
\multicolumn{4}{c}{ TABLE 4.1: RESPONSE RATE } \\
\hline \hline & Responses & Frequency & Percentage \\
\hline 1 & Returned & 114 & $95 \%$ \\
& Unreturned & 6 & $5 \%$ \\
& Total & 120 & 100 \\
\hline \hline
\end{tabular}

\section{B. Regression Analysis Results}

In order to address the study main objective; "to establish the influence of lean inventory management systems on performance of supermarkets in Nairobi City County", the study regressed lean inventory management systems (just in time, cross-docking, backordering and drop picking) against performance as follows:

Performance $=\beta 0+\beta 1 \mathrm{JIT}+\beta 2 \mathrm{CD}+\beta 3 \mathrm{BD}+\beta 4 \mathrm{DP}+\mathcal{E}$ based on the conceptualized model in chapter 2 where: $\mathrm{Y}=$ Performance, $\mathrm{B} 0=$ Constant, B1, B2, B3 and B4 are regression coefficients respectively, JIT $=$ just in Time, $\mathrm{CD}$ $=$ Cross docking, $\mathrm{BD}=$ Backordering, $\mathrm{DP}=$ Drop picking.

The model measurement $r$ denoted the strength and direction of the linear relationship between the variables, and $R$ - squared $\left(R^{2}\right)$ value indicated the percentage of performance impacted by the independent variables. A t-test was also done at a $P$-value of significance level $p \leq 0.05$. The 
result of the MRM are presented on Table 4.2. The model Coefficient of determination $\left(R^{2}\right)$ was found to be 0.342 showing that $34.2 \%$ of supermarket performance was explained by the independent factors under study. The results from the table show that, the predictor equation for procurement performance $(\mathrm{Y})$ versus independent factors (Xi) takes the form of:

Supermarket performance $=2.950+0.335$ (Just in time) + 0.038 (Cross - docking) + 0.287 (Backordering) +0.272 (Drop picking)

This means that, supermarket performance increases by 0.335 when Just in time inventory management system went up by 1 ; Increases by 0.038 when cross - docking management systems went up by 1 ; Increases by 0.287 when backordering inventory management systems went up by 1 ; and increases by 0.272 when Drop picking inventory management system went up by 1 .

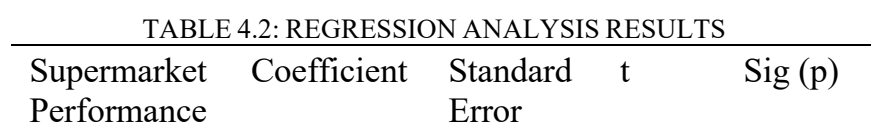

\begin{tabular}{|c|c|c|c|c|}
\hline Just in time & 0.335 & 0.050 & 2.965 & 0.000 \\
\hline $\begin{array}{l}\text { Cross- } \\
\text { Docking }\end{array}$ & 0.038 & 0.043 & 0.753 & 0.030 \\
\hline Backorderin & 0.287 & 0.104 & 2.232 & 0.016 \\
\hline $\begin{array}{l}\text { g } \\
\text { Drop } \\
\text { Picking }\end{array}$ & 0.272 & 0.120 & 1.950 & 0.020 \\
\hline Constants & 2.950 & 1.282 & 2.277 & 0.025 \\
\hline
\end{tabular}

\section{Discussion of the results}

The study objective was to establish the influence of lean inventory management systems on the performance of supermarkets in Nairobi County, Kenya. This study was grounded on RBVT as advocated by [7], [4]; and [18] that lean inventory management systems positively influence firm performance. The study findings revealed that, supermarkets that have deployed the use of lean inventory management systems within their operations experience improvement in performance. The regression analysis results indicate that lean inventory management has a positive statistically significant effect on supermarket performance; $p<0.05(P=0.000)$ with an explanatory power of 34.2 percent. Therefore, the study null hypothesis "lean inventory management systems do not influence performance of supermarkets in Nairobi City County" was rejected and alternative accepted. Specifically, the study reveals that just in time and backordering had the highest influence respectively and the least was cross-docking.

The findings of this study strongly agrees with previous studies conducted by [3] which reveal that lean practices are critical for the performance of firms. It supports the RBV theorists [7], [4]; and [18] views. Further, the study is in agreement with [15] and [16] who utilized the RBV theory in determining the relationship between lean systems and supply chain performance. The study revealed that there was a positive correlation between lean strategies and firm performance.

\section{SUMMARY, CONCLUSION AND RECOMMENDATIONS}

\section{A. Summary of Findings}

The study objective was "to establish the effect of lean inventory management systems on the performance of supermarkets in Nairobi City County". The study findings rejected the null hypothesis, "there is no significant relationship between LIMSs and performance of supermarkets in Nairobi City County" and accepted the alternative. The study established that within LIMSs, the system with the highest influence on performance was just in time, followed by backordering, drop picking and crossdocking respectively. Further, the study established that the use of a leanrinpentory management systems such as just-intime (JIT), cross-docking, drop shipping and backordering not only amprienes the efficiency of the procurement function but also positively impacts firm performance.

\section{B. Conclusion}

The study established a significant positive relationship between lean inventory management systems and supermarket performance. A positive increase in the utilization of lean inventory management systems increases the performance of supermarkets. The study therefore concludes that the employment of Lean inventory management systems such as Just-in-time, Back-ordering, drop-shipping and cross-docking improves supermarket performance.

\section{Recommendations of the Study}

Based on the study findings that LIMSs positively significantly influence the performance of supermarkets and in line with [2] and [18] assertion that lean systems reduce costs, increase efficiency, reduce execution time, reduce waste of all kinds, increase profitability and keep low inventories, the study recommends the following: retail supermarket owners/managers should implement an inventory policy in support of lean inventory management practices, define stock keeping units to better understand and forecast demand. Secondly, supermarket owners should make profound cultural changes to re-enforce a lean transformation and develop a performance culture focusing continuous improvement where staff are always actively discussing and implementing improvements through either formal or informal. Finally supermarket owners/managers need to close the gap by hiring a few people with lean expertise and experience from outside the retail sector to seed the transformation and build new internal capabilities in lean inventory management practices in managing their inventory. 


\section{Areas for Further Research}

The study was limited to supermarkets in Nairobi City County which may not be representative enough in terms geographical of the coverage, population size and sector wise. Therefore, a similar study is recommended targeting other sectors, larger population and a diverse geographical area for in depth understand of the subject. Since this was a cross-sectional study, a longitudinal study is recommended to capture the trend of the relationship over time before conclusively drawing conclusion.

\section{REFERENCES}

[1] J.B Barney and D.N. Clark, Resource-Based Theory: Creating and Sustaining Competitive Advantage: Creating and Sustaining Competitive Advantage, OUP Oxford, U.K.: 2007.

[2] G. Distelhorst, J. Hainmueller and R. Locke, "Does lean improve standards? Management and performance in the Nike supply chain", Management Science, 63(3), 707-728, 2016.

[3] I. Elking, J. P. Paraskevas, C. Grimm, T. Corsi and A. Steven, "Financial dependence, lean inventory strategy and firm performance", Journal of Supply Chain Management, 53(2), 2238, 2017.

[4] J. Fahyl, The Role of Resources in Global Competition, London, United Kingdom, Routledge, 2002.

[5] K. Govindan, "The optimal replenishment policy for time-varying stochastic demand under vendor managed inventory". European Journal of Operational Research, 242(2), 402-423, 2015.

[6] K.Govindan, G. Azevedo, H. Carvalho, and V. Cruz-Machado, "Lean, grean and resilient practices influence on supply chain performance: interpretive structural modelling approach", International Journal of Environmental Science and Technology, 12(1), 15-34, 2015

[7] R. M. Grant, Contemporary Strategy Analysis: Text and Cases, $(8$ edition), Chichester, West Sussex, United Kingdon: Wiley, 2013.

[8] J. Hahn, and J. Packowski, "A perspective on application of in memory analytics in supply chain management. Decision Support Systems," International Journal of Business 76(2), 45-52, 2015.

[9] R. Kagwanja, and P. Mwangangi, "The Influence of Supply Chain Integration on Firm Performance in Kenya: A Case of DHL Kenya". International Journal of Human Resource and Procurement, 4(4), 13-25, 2015.

[10] I. Kennedy, A. Plunkett, and J. Haider, "Implementation of lean principles in a food manufacturing company. Advances in Sustainable and Competitive Manufacturing Systems", Journal of Logistics Purchasing and Supply Chain Management, 8 (3) 15791590, 2013.

[11] S. S. Kitheka and G. O. Ondiek "Inventory Management Automation and the Performance of Supermarkets in Western Kenya", International Journal of Research in Management \& Business Studies, 1(4), 9-18, 2015.

[12] M. A. Lewis and J. K. Roehrich, "Contracts, relationships and integration: towards a model of the procurement of complex performance", International Journal of Procurement Management, 2(2), 125-142, 2009.

[13] T.Lwiki, P. B. Ojera, N. Mugenda and V. Wachira, "The impact of inventory management practices on financial performance of sugar manufacturing firms in Kenya", International Journal of Business, Humanities and Technology, 3(5), 75-85, 2013.

[14] M. E. Mongare and S. E. Nasidai, "The impact of information communication technology on inventory control systems in transport organization: A case study of Kenya ferry services", European Journal of Logistics, Purchasing and Supply Chain Management, 2(1), 17-41, 2014.

[15] O. Mugenda, and A. Mugenda, Research Methods: Quantitative \& Qualitative Approaches. Nairobi, Kenya: African Centre for Technology Studies, 2003.

[16] S. Qrunfleh and M. Tarafdar, "Supply Chain information systems strategy: Impacts on supply chian performance and firm performance", International Journal of Production Economics, $147,340-350,2014$.
[17] F. Sheikh, The role of vendor Managed inventory on supply chain performance in distribution section in Kenya: A case of Unga Ltd. Mount Kenya University, Nairobi, Kenya, JKUAT, 2016

[18] M. Thogori and J. Gathenya, "Role of Inventory Management on Customer Satisfaction among the Manufacturing Firms in Kenya: A Case Study of Delmonte Kenya", European Journal of Operational Research, 215(2), 301-325, 2014.

[19] K. Veera and B. Muhammad, "Supply Chain Practices and Performance: The Indirect Effects of Supply Chain Integration", Benchmarking: An International Journal, 23(6), 1445-1471, 2016.

[20] V. Shardeo, "Impact of Inventory Management on the Financial Performance of the firm". IOSR Journal of Business and Management (IOSR-JBM), 7(4), 1-12, 2017.

[21] J. C. Nunnally, Assessment of Reliability. In: Psychometric Theory (2nd Ed.). New York: McGraw-Hill, 1978.

[22] Y. Taro, Statistics: An Introductory Analysis, 2nd Edition, New York: Harper and Row.1967.

[23] Kenya National Bureau of Statistics. National Economic Survey, Nairobi, Kenya, KNBS, July, 1, 2017

[24] Dvir, Nim, Gafni and Ruti. "When Less Is More: Empirical Study of the Relation Between Consumer Behavior and Information Provision on Commercial Landing Pages". Informing Science: The International Journal of an Emerging Trans discipline. 21: 019039, 2018.

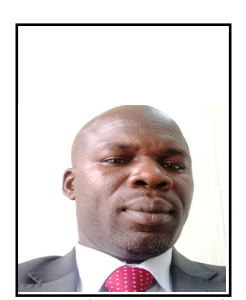

Achuora John was born in Migori County, Kenya in $1^{\text {st }}$ August 1978. In the year 2015, he earned a PhD degree in Supply Chain Management from Jomo Kenyatta University of Agriculture and Technology, Juja, Kenya; in 2011, he earned MSc. degree in Procurement and Logistics Management from JKUAT, Juja, Kenya and in the year 200, he earned Bachelor of Commerce degree (Accounting) degree from Sukhadia University, Udaipur, India.

$\mathrm{He}$ is a researcher who has worn several grants and published several authoritative papers in reputable journals in the area of SCM. He lectures and coordinates exams at Machakos University, Machakos Town, Kenya. $\mathrm{He}$ is an external examiner at Management University of Africa, adjunct lecturer at Masinde Muliro University of Science and Technology and a reviewer of Global Scientific Journal. He was supply chain Management leader at Itumo International Ltd, Procurement Manager at United States International University- Africa, Assistant Procurement manager at Hyoung and Co. E.A. Ltd, and Procurement officer at Icon Telesec Services Ltd.

Dr. Achuora is a Supply chain Management specialist and Procurement Systems developer and Analyst, Certified Procurement Practitioner by Kenya Institute of Supplies Management, Certified International Procurement Practitioner by IAPM, licence supplies management practitioner by KISM and a Member of Kenya Institute of Management (KIM). 